\title{
Small signal fault analysis for renewable energy (wind) power system distributed generation by using MATLAB software (simulink)
}

\author{
Ameerul A. J. Jeman ${ }^{1}$, Naeem M. S. Hannoon ${ }^{2}$, Nabil Hidayat ${ }^{3}$, Mohamed M. H. Adam ${ }^{4}$, \\ Ismail Musirin ${ }^{5}$, Vijayakumar $\mathrm{V}^{6}$ \\ 1,2,3,4,5Faculty of Electrical Engineering, Universiti Teknologi MARA (UITM), Malaysia \\ ${ }^{6}$ School of Computing Science and Engineering, VIT University Chennai, India
}

\begin{tabular}{l} 
Article Info \\
\hline Article history: \\
Received Aug 28, 2018 \\
Revised Nov 10, 2018 \\
Accepted Dec 5, 2018 \\
\hline Keywords: \\
DFID \\
Doubly fed induction generator \\
DSTATCOM \\
Renewable energy \\
STATCOM
\end{tabular}

Article Info

Article history:

Received Aug 28, 2018

Revised Nov 10, 2018

Keywords:

DSTATCOM

STATCOM

\begin{abstract}
In distribution system, wind power plants are becoming popular renewable energy sources. It employs Doubly Fed Induction Generator (DFIG) to generate power based on wind conversion. Short and long transmission lines, presence of faults and presence of Static Synchronous Compensator (STATCOM) are highlighted issues in this paper. Basically, this research develops investigations on some electrical variables such as voltage and current to control them. Distribution Static Synchronous Compensator (DSTATCOM) is proposed in this paper. Wind farm acts as a source while DSTATCOM is connected to the distribution system with a DFIG based wind farm. The controller proposed is DSTATCOM is modeled and simulated in MATLAB/SIMULINK and the results are given. A microgrid based small signal analysis is performed in the laboratory using MATLAB and different comparisons are made and simulation case studies are presented and validated.
\end{abstract}

Corresponding Author:

Naeem M. S. Hannoon,

Faculty of Electrical Engineering,

Universiti Teknologi MARA (UiTM), 40450 Shah Alam, Selangor, Malaysia.

Email: hannoon.naeem@gmail.com

\section{INTRODUCTION}

Fault in electrical equipment or apparatus is defined as an imperfection in the electrical circuit due to which current is deflected from the intended path. Renewable energy often provides energy in four important areas which are electricity generation, air and water heating or cooling, transportation, and rural (off-grid) energy services. Sustainable power (sources) or RES catch their vitality from existing streams of vitality, from on-going characteristic procedures, for example, daylight, wind, streaming water, natural procedures, and geothermal warmth streams. In other words, the fault is the abnormal condition of the electrical system which damages the electrical equipment and disturbs the normal flow of the electric current.

A wind farm is a group of wind turbines in the same location and it is used to provide electricity. An electrical energy producer is utilizing the renewable energy sources such as wind, solar, geothermal and biomass. The wind energy has lots of meaningful advantages with respect to other sources in terms of generation costs and installation. Wind cultivate is a region of land with a bunch of twist turbines for driving electrical generators. The wind energy is converted to electrical energy by the use of a generator. Wind turbine structure of the six-bladed turbine. Wind energy has knowledgeable an extraordinary expansion in recent years. The wind farm is aged, their operations are very complicated are gaining implications. Wind industries meet exaggerated failures due to failure of wind turbine equipment [1]. 
Output voltage during fault at short transmission line and long transmission line are different. Not many researchers highlighted the effect of changing transmission line on the voltage profiles of distributed generation. Besides that, there is no specific system to regulate voltage in power system to determine the location of distributed generation issues. The objectives of this research are as follows;

1) To study the power system oscillation during single-phase fault.

2) To analyze the voltage profile and fault level at short and long transmission lines.

3) To propose a strategy system that regulates voltage profiles in power system.

In this project, the focused study is to analyze the fault of distributed generation for renewable energy. With the aid of software tools, the verification of a proposed strategy to study the fault analysis for renewable energy (wind) power system distributed generation during outage is completed.

The fault ride through capability of renewable energy sources for providing support to the power grid under several disturbances allow people to researchers to consider them not only as passive elements in the power system network, but also as additional services for the mitigation of evolving contingencies. In electrical power designing, fault ride through (FRT), once in a while under-voltage ride through (UVRT) or Low voltage ride through (LVRT), is the capacity of electric generators to remain associated in brief times of lower electric system voltage. For smoother fault recovery, a critical dead band zone modification is suggested [2].

Since renewable energy source network has the ability to transmit large power over a long distance with less loss and without any need of synchronization, it needs high voltage direct current (HVDC) transmission [3]. For long-separate power transmission, HVDC lines are more affordable, and misfortunes are less when contrasted with AC transmission.

A lot of power systems are facing power quality problems and transmission equipment are stressed with heavy power flows over long distances [4]. Power Quality or Voltage Quality alludes to the changing of the ideal sinusoidal voltage waveform to non-sinusoidal or mutilated voltage waveform. Distributed generation (DG) units can minimize the burden on transmission networks by supplying local loads and providing ancillary services. The other way round, increased penetration of DG units in the distribution networks require new operating conditions to ensure safe and secure system operation. This concern appears during the operation of small to medium-scale low and medium voltage micro grids.

In recent years the number of renewable energy generators connected to Ireland's electricity grid has steadily increased. The Republic of Ireland is now expected to source $13.2 \%$ of the electricity it consumes from renewables by 2010, which represents a significant challenge to the electricity system operators and planners [5]. They described the modelling and simulation of a small hybrid wind and hydro generating plant connected to the distribution network. They investigated the effects upon the plant of transmission network faults and continuous voltage unbalance. Voltage unbalance can cause three-phase engines and other threephase burdens to encounter poor execution or untimely disappointment in light of the accompanying; mechanical worries in engines because of lower than typical torque yield, unbalance current will stream in impartial conductors in three-stage wye frameworks and higher than ordinary current in engines and threestage rectifiers.

In a wind turbine energy system reviewed, most applications of data mining had been overwhelming. The biggest challenge in the world is wind power predictions [1]. Wind energy research involving wind turbine control, turbine monitoring and detection of fault are surveyed. Particular faulty components are identified. Wind turbine conditions are monitored and fault defects are analyzed. High level of wind energy penetration into the grid system results in operation constraints to avoid any tripping out of wind generators from the grid during fault conditions [6].

The detection and classification of power system faults is an important task for the relaying system. The relay system recognizes the deplorable or bothersome condition with a doled out region and gives the charges to the electrical switch to disengage the influenced region. The relaying is an important aspect for the protection of transmission lines, generators, bus-bars, and transformers for reliable power system operation [7]. The accurate fault location is a very challenging task for protection of power transmission line. The faulty system can be restored as early as possible if the accurate locations of faults are known. Nowadays, renewable energy source such as wind has increased significantly.

In the extra high voltage transmission line, the transient components are introduced during the faulty conditions. The transients may damage the power system equipment as well as may also lead to the maloperation of the equipment utilized for a specific application in the power network. Transient surges are characterized as fleeting blasts of vitality that are prompted upon control. These transient components are intensified in the presence of distributed generation sources such as wind and solar power generation [8]. 


\section{RESEARCH METHOD}

This paper is simulated by using software (MATLAB Simulink 2010). The voltage versus time is observed for this research. This simulation of wind turbine produces $9 \mathrm{MW}$ connected to the main grid which will be used during islanding in order to provide continuous electricity to micro-grid. The manipulated variables in this research are the length of transmission line, faulty presence and STATCOM presence, as shown in Figure 1.

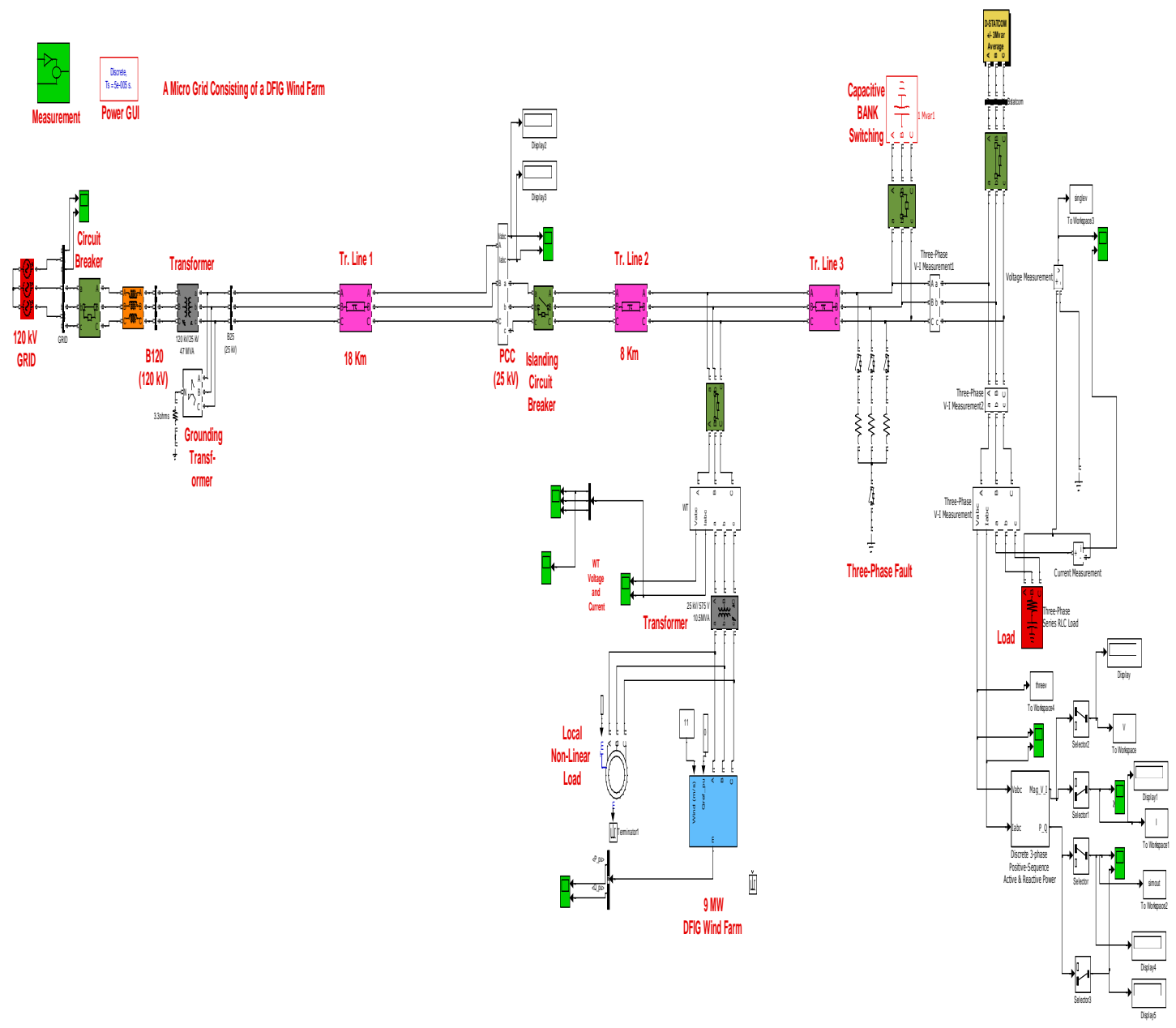

Figure 1. Overall circuit of the system (wind farm)

DFIG is great since it can work in a higher breeze speed range and yield or devour receptive power through the polarization gave. As a breeze turbine driven on DFIG, AC-DC-AC converter, wind turbine control, wound rotor enlistment generator, drive prepare and turbine are incorporated inside it. Turbine speed can be upgraded and DFIG will permit the extraction of greatest vitality from the breeze for low breeze speeds, while constraining mechanical weight on the turbine amid whirlwinds.

The purpose of normal coupling where the DSTATCOM is connected to. PCC otherwise called purpose of normal coupling is where conveyed age (DG) units are coupled together. It additionally provided to the heap. In this paper, DFIG works in islanding mode. The DSTATCOM is essentially a voltage source inverter with a DC capacitor in the info. This DC capacitor is essentially the wellspring of the receptive power that is provided by the DSTATCOM.

Voltage source inverter (VSC) is the primary unit of DSTATCOM which changes over the DC voltage over the capacity gadget into an arrangement of three-stage AC yield voltages. The circulation framework is in stage and combined with these voltages through the reactance of the coupling transformer. The capacity of VSC is to infuse the distinction between the evaluated voltage and the voltage amid the hang condition, and to totally supplant the voltage.

Small signal fault analysis for renewable energy (wind) power system distributed.... (Ameerul A. J. Jeman) 
DSTATCOM is Distribution Static Compensator and an individual from the CPD family. Goes about as a custom power gadget, it is shunt associated with the dissemination framework and it helps in infusing current through an interfacing inductor at the purpose of regular coupling. For the most part, to control a DSTATCOM, the terminating of the entryway terminals is the key [9]. There are a couple of sorts of controls accessible, for example, Synchronous reference outline control (SRF), solidarity control factorbased control (UPF), Instantaneous responsive power hypothesis (IRPT) and the sky is the limit from there.

To evaluate the separation between the reference focuses and the individual breeze turbine utilizing an Euclidean separation [10]. The ongoing matrix controls with respect to renewable energy sources interconnection characterize that under low-voltage network blames, the sustainable power sources ought to stay interconnected [11-15].

\section{RESULTS AND ANALYSIS}

\subsection{Short Transmission $(0.5 \mathrm{~km})$}

As shown in Table 1 and Table 2, the results are at $0.5 \mathrm{~km}$ without fault during islanding. When STATCOM is not connected in the grid, the voltage reading at the load is higher than when STATCOM is connected in the grid. However, when STATCOM is connected to the grid, reactive power, Q is absorbed which makes the reactive power reading becomes very close to zero. Before STATCOM is connected, the reactive power is not stable and below zero.

Table 1. Coparison Resut without Statcom and with Statcom (without Fault) at $0.5 \mathrm{Km}$

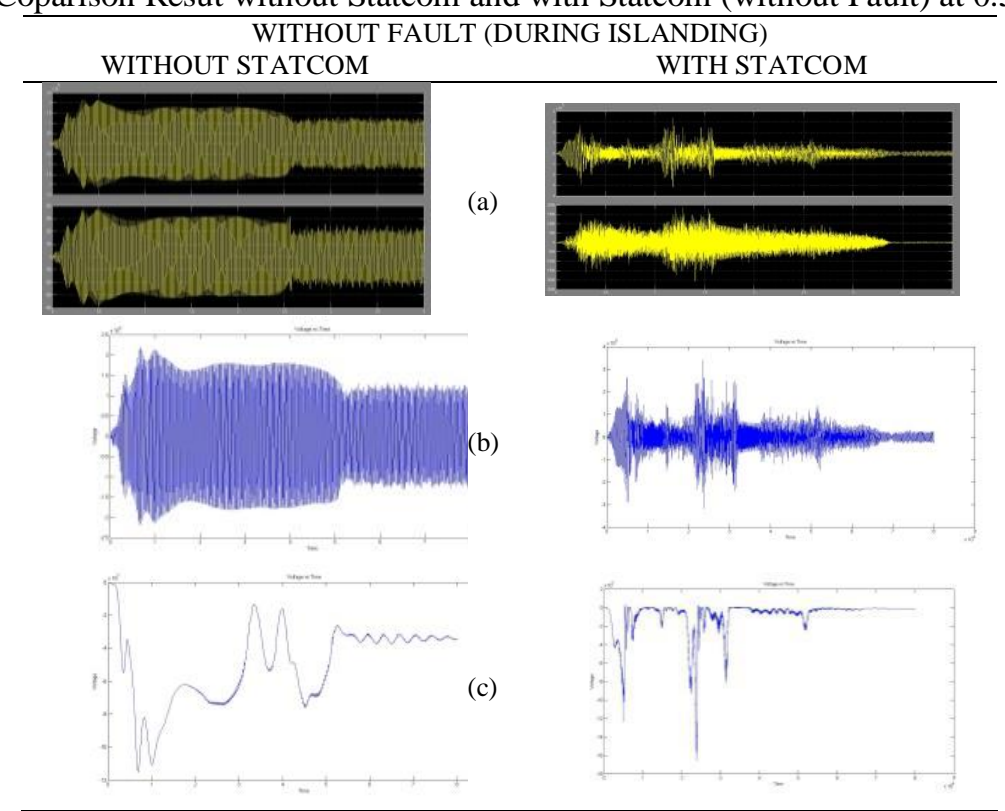

(a) Graph of voltage and current versus time

(b) Graph of voltage versus time

(c) Graph of reactive power versus time

Table 2. Value Taken when the Graph is Constant (4 S)

\begin{tabular}{ccc}
\hline \multicolumn{3}{c}{ WITHOUT FAULT (DURING ISLANDING) } \\
WITHOUT STATCOM & WITH STATCOM \\
\hline 114.9 & Voltage (kV) & 21.65 \\
201.9 & Current (I) & 38.3 \\
-34.3 & Reactive Power (MVar) & -1.231 \\
\hline
\end{tabular}

As shown in Table 3 and Table 4, the results are at $0.5 \mathrm{~km}$ with fault during islanding. Fault is set to happen from $1.5 \mathrm{~s}$ to $2.0 \mathrm{~s}$. Without STATCOM, the voltage shoots up very high from the normal voltage and the reactive power below zero and not in a steady state at all. The shooting up voltage must be avoided since it can cause damages to the load or any other equipment. However, with STATCOM, the shooting up voltage 
can be controlled back to the normal range. The reactive power when STATCOM absorbed it is more stable and reaching to zero.

Table 3. Coparison Resut without Statcom and with Statcom (with Fault) at $0.5 \mathrm{Km}$

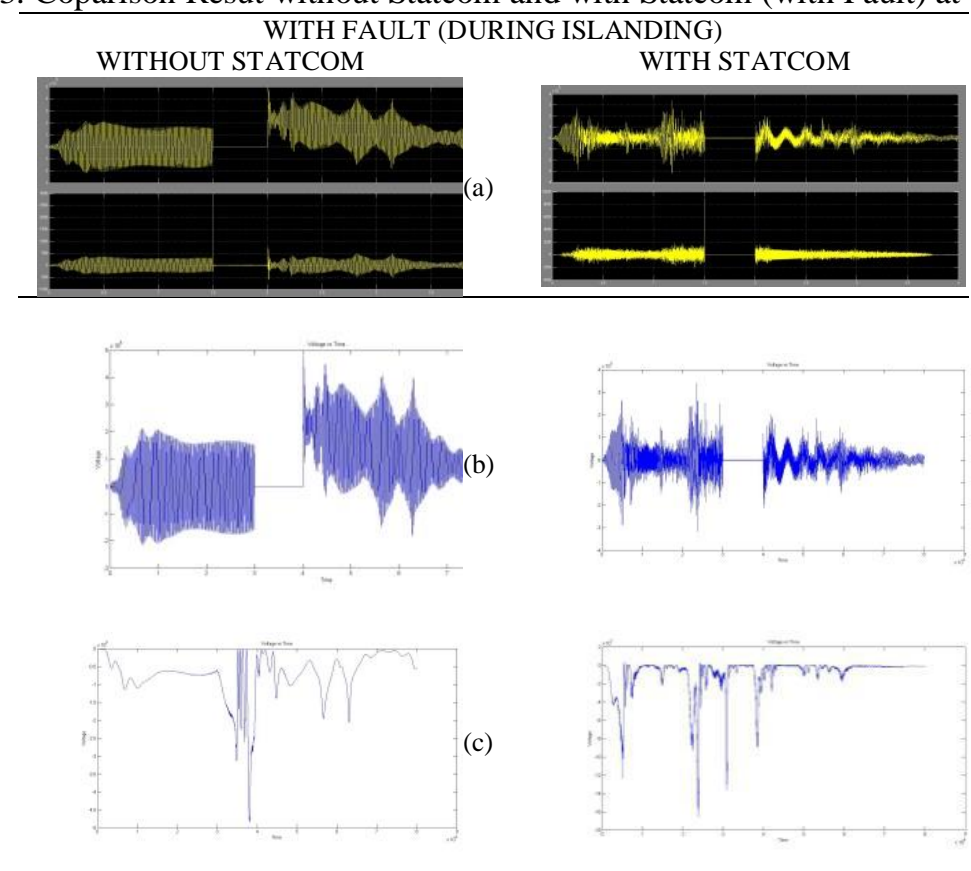

(a) Graph of voltage and current versus time

(b) Graph of voltage versus time

(c) Graph of reactive power versus time

Table 4. Value Taken when Graph is Constant $(4 \mathrm{~S})$

\begin{tabular}{ccc}
\hline \multicolumn{3}{c}{ WITH FAULT (DURING ISLANDING) } \\
WITHOUT STATCOM & WITH STATCOM \\
\hline 149.1 & Voltage (kV) & 15.89 \\
255.2 & Current (I) & 30.12 \\
-56.95 & Reactive Power (MVar) & -0.7221 \\
\hline
\end{tabular}

\section{a. Long Transmission (5 km)}

As shown in Table 5 and Table 6 , the results are at $5 \mathrm{~km}$ without fault during islanding. When the grid without STATCOM is compared to the grid with STATCOM, the voltage reading is higher. Once reactive power is absorbed by the STATCOM, the voltage and reactive power become better in terms of the stability. The reactive power when there is no STATCOM always far from zero but when there is STATCOM, it controls it back so that it can become near to zero.

Table 7 and Table 8, the results are at $5 \mathrm{~km}$ with fault during islanding. Fault is set to happen from $1.5 \mathrm{~s}$ to $2.0 \mathrm{~s}$. The voltage shoots down a bit when there is no STATCOM. STATCOM must be installed to recover that problem. After the installation of STATCOM, the voltage reading becomes more stable toward the end of the graph. As for the reactive power, it becomes steady state towards the end of the graph after the STATCOM is installed into the grid system.

Table 9 and Table 10 show the comparison of voltages and reactive powers at $0.5 \mathrm{~km}$ and $5 \mathrm{~km}$ respectively. The values are tabulated to see whether voltage or reactive power increase or decrease at certain condition. 
Table 5. Comparison Result without Statcom and with Statcom (without Fault) at $5 \mathrm{Km}$ WITHOUT FAULT (DURING ISLANDING)

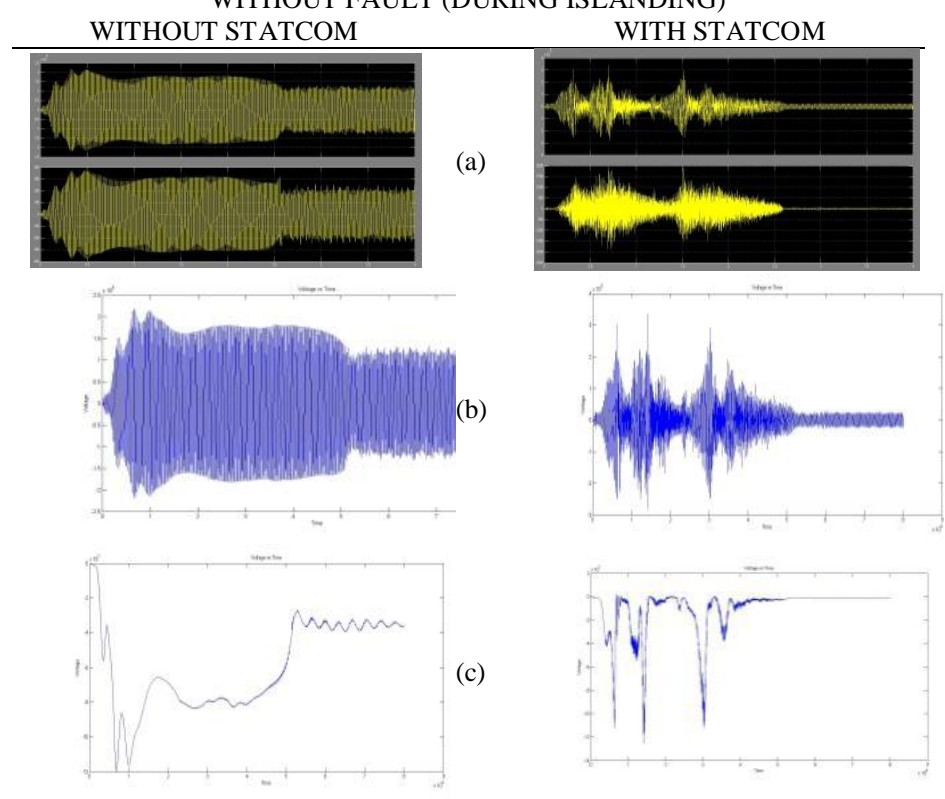

(a) Graph of voltage and current versus time

(b) Graph of voltage versus time

(c) Graph of reactive power versus time

Table 6. Value Taken when the Graph is Constant (4 s)

\begin{tabular}{ccc}
\hline \multicolumn{3}{c}{ WITHOUT FAULT (DURING ISLANDING) } \\
WITHOUT STATCOM & WITH STATCOM \\
\hline 117.4 & Voltage (kV) & 22.08 \\
207.1 & Current (I) & 36.4 \\
-36.12 & Reactive Power (MVar) & -1.142 \\
\hline
\end{tabular}

Table 7. Comparison Result without Statcom and with Statcom (with Fault) at $5 \mathrm{Km}$

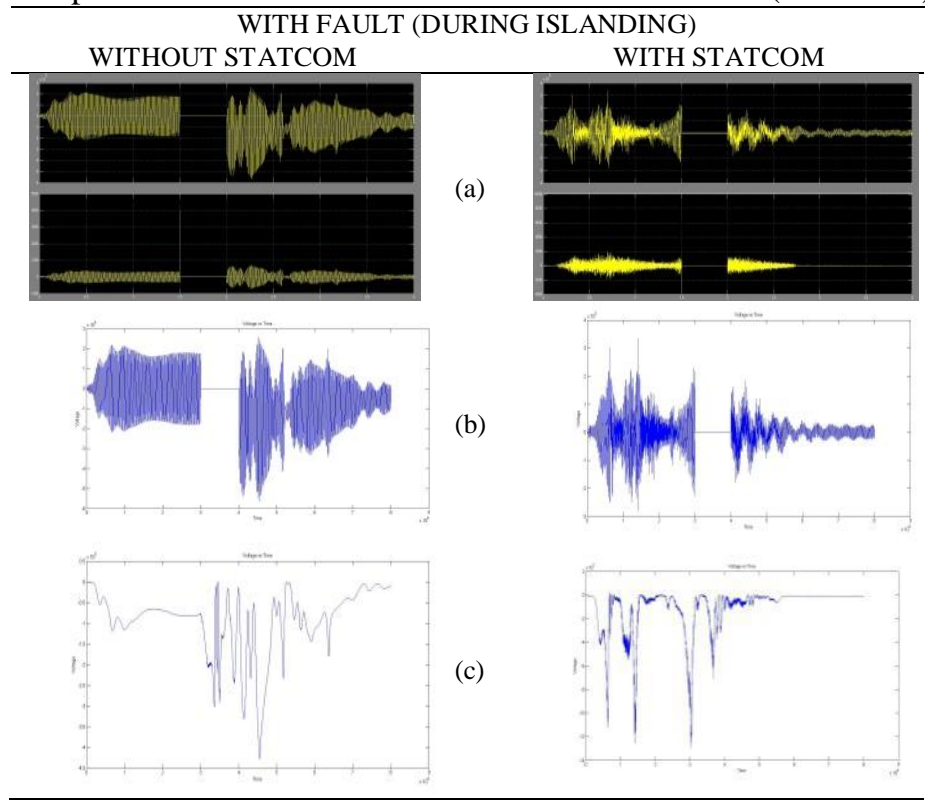

(a) Graph of voltage and current versus time

(b) Graph of voltage versus time

(c) Graph of reactive power versus time 
Table 8. Value Taken when the Graph is Constant (4 S)

\begin{tabular}{ccc}
\hline \multicolumn{3}{c}{ WITH FAULT (DURING ISLANDING) } \\
WITHOUT STATCOM & WITH STATCOM \\
\hline 65.31 & Voltage $(\mathrm{kV})$ & 23.46 \\
117.6 & Current (I) & 38.94 \\
-11.18 & Reactive Power (MVar) & -1.114 \\
\hline
\end{tabular}

Table 9. Comparison of Voltages (KV) between $0.5 \mathrm{Km}$ and $5 \mathrm{Km}$

\begin{tabular}{cccc}
\hline & & $0.5 \mathrm{~km}$ & $5 \mathrm{~km}$ \\
\hline WITHOUT & WITHOUT STATCOM & 114.9 & 117.4 \\
FAULT & WITH STATCOM & 21.65 & 22.08 \\
WITH & WITHOUT STATCOM & 149.1 & 65.31 \\
FAULT & WITH STATCOM & 15.89 & 23.46 \\
\hline
\end{tabular}

Table 10. Comparison of Reactive Power (MVAR) between $0.5 \mathrm{Km}$ and $5 \mathrm{Km}$

\begin{tabular}{cccc}
\hline & & $0.5 \mathrm{~km}$ & $5 \mathrm{~km}$ \\
\hline WITHOUT & WITHOUT STATCOM & -34.3 & -36.12 \\
FAULT & WITH STATCOM & -1.231 & -1.142 \\
WITH & WITHOUT STATCOM & -56.95 & -11.18 \\
FAULT & WITH STATCOM & -0.7221 & -1.114 \\
\hline
\end{tabular}

\section{CONCLUSION}

While the conduction of the plan for wind farm, steps of precaution were taken against islanding. It was due to the prevention of catastrophic consequences for equipment connected to the islanding network.

From the results, fault had shown that it could make a change to the voltage graph at the load. The change was in terms of the magnitude of the voltage after fault had occurred. However, when controller (STATCOM) had been installed, it could regulate the voltage back to the normal range. Towards the end of the graph, the voltage signal became steady which put it in steady state form. The voltage magnitude depended on the reactive power.

During no STATCOM, the reactive power graphs were below zero. That referred to both cases which were short transmission line $(0.5 \mathrm{~km})$ and long transmission line $(5 \mathrm{~km})$. STATCOM acted as a controller, it absorbed reactive power from the grid system. Once reactive power from is absorbed by STATCOM from the grid system, the reactive power graph reached to zero and in steady state mode very near to zero. When reactive power was absorbed, it reduced the voltage.

The behavior depicted was quite different from the normal power system during islanding. To control the system, STATCOM had been designed. As a recommendation, hopefully, in the future, more researches and results will be gained from these experiments. A better controller can be designed to gain the desired voltage for this research.

\section{ACKNOWLEDGEMENTS}

The author and researchers sincerely thank IRMI, 600-IRMI/DANA 5/3/LESTARI (0169/2016), and UiTM for providing lab facility and the fund to conduct this research smoothly.

\section{REFERENCES}

[1] M. Kokila and P. I. Devi, "A Survey of Wind Turbine Control Monitoring and Fault Detection on Wind Energy," 2016 Int. Conf. Comput. Technol. Intell. Data Eng., 2016.

[2] L. Hadjidemetriou, et al., "Investigation of different Fault Ride Through strategies for renewable energy sources," 2015 IEEE Eindhoven PowerTech, PowerTech 2015, 2015.

[3] C. S. Syamdev and A. A. Kurian, "HVDC fault tolerant converter for renewable energy source grid," 2014 Int. Conf. Adv. Green Energy, ICAGE 2014, pp. 184-190, 2014.

[4] F. Alsokhiry and K. L. Lo, "Effect of distributed generations based on renewable energy on the transient fault Ride through," Proc. 2013 Int. Conf. Renew. Energy Res. Appl. ICRERA 2013, pp. 1102-1106, 2013.

[5] J. F. Conroy, et al., "Investigation of the Effects of Transmission Faults upon a Renewable Energy Generating Plant," pp. 1-7.

[6] M. A. H. El-Sayed and M. M. A. M. Aly, "Enhanced fault location algorithm for smart grid containing wind farm using wireless communication facilities," IET Gener. Transm. Distrib., vol/issue: 10(9), pp. 2231-2239, 2016.

[7] A. K. Ishtiak, "Fault Analysis and Detection Techniques of Solar Cells and PV Modules," 2nd Int'l Conf. on Electrical Engineering and Information \& Communication Technology (ICEEICT), 2015.

[8] S. Aniva, et al., "Analysis of Faults on Series Compensated EHV Transmission Line in The Presence of Wind Generation." 
[9] B. Singh, et al., "Modelling Design and Analysis Of Different Controllers For DSTATCOM," POWERCON 2008. IECON 2009, 35th Annual Conference IEEE.

[10] A. Kusiak, "Monitoring Wind Farms with Performance Curves," IEEE transactions on sustainable energy, 2012, pp: $1-8$

[11] IEEE Standard for Interconnecting Distributed Resources With Electric Power Systems, IEEE Std 1547-2003, pp. $1-27,2003$.

[12] I. Erlich, W. Winter, and A. Dittrich, "Advanced grid requirements for the integration of wind turbines into the German transmission system," in Proc. of IEEE-PES General Meeting, Montreal, Canada, pp. 1253- 1257, 2006.

[13] B.-I. Craciun, T. Kerekes, D. Sera, and R. Teodorescu, "Overview of recent grid codes for PV power integration," in Proc. OPTIM, Brasov, Romania, pp. 959-965, 2012.

[14] R. Teodorescu, M. Liserre, and P. Rodriguez, Grid Converters for Photovoltaic and Wind Power Systems. John Wiley \& Sons, 2011.

[15] L. Hadjidemetriou, E. Kyriakides, and F. Blaabjerg, "an adaptive tuning mechanism for phase-locked loop algorithms for faster time performance of interconnected renewable energy sources," IEEE Trans. Industry Applications, pp. 1-13, 2015. 